\title{
CARLOS GARDEL COMO PATRIMÔNIO CULTURAL NA ARGENTINA
}

\author{
Alessander Mário Kerber ${ }^{1}$
}

\section{Introdução}

No presente artigo analiso as "ativações patrimoniais"2 realizadas em Buenos Aires para promover Carlos Gardel como patrimônio imaterial dessa cidade e da nação desde 1998. Para tanto, utilizo, como fontes, a materialidade resultante dessas ações realizadas pelo governo municipal de Buenos Aires: a legislação estabelecida, as intervenções estabelecidas no bairro do Abasto - especialmente a criação do Museo Casa Carlos Gardel - e as publicações produzidas no intuito de afirmar Gardel como portenho e argentino. Em pesquisa realizada anteriormente, demonstrei como Gardel construiu uma versão sobre a identidade nacional argentina em suas músicas, imagem e performances, como o próprio artista frequentemente se apresentou como representante dessa nação e como essa versão teve sucesso entre os seus públicos argentinos (constituindo motivo de disputa com os uruguaios) no período entre 1916 e 1935. No presente artigo, abordando um contexto histórico muito distinto, demonstro como as discussões recentes acerca do patrimônio imaterial trouxeram novamente à tona um nacionalismo argentino verificável nas ações realizadas de promover Gardel como patrimônio argentino e portenho.

\section{Gardel como Representação da Identidade Nacional Argentina}

As ativações patrimoniais realizadas recentemente na Argentina para preservar e promover Carlos Gardel como patrimônio cultural daquele país e da cidade de Buenos Aires estabelecem uma relação de consequência e continuidade em relação ao contexto no qual o artista viveu e em relação à memória construída após seu falecimento, em 1935. Além de ser o cantor de maior sucesso, Gardel tornou-se representação da identidade nacional argentina durante sua trajetória artística e consagrou-se desta forma com sua morte prematura em uma queda de avião.

Gardel realizou sua trajetória artística entre os anos 1910 e 1930, período em que houve, na Argentina, um grande processo de renegociação, redefinição e massificação de determinadas representações da identidade nacional em que o tango deixou de ser estilo musical excluído e tornou-se representação nacional. O sucesso do tango em Paris desde a década de 1910 e o próprio sucesso nacional e internacional de Gardel já a partir daquela década explicam, em grande medida, o

\footnotetext{
${ }^{1}$ Doutor em História pela Universidade Federal do Rio Grande do Sul. Realizou estágios pós-doutorais na Universidad Nacional de Cuyo, Argentina (2013), com uma bolsa Capes, e na Universidade de São Paulo (2013/ 2014). Professor Adjunto do Departamento de História e do Programa de PósGraduação em História da Universidade Federal do Rio Grande do Sul. Líder do Grupo de Pesquisa "História das Culturas e Identidades Brasileiras e Latino-Americanas" (Diretório CNPq), Editor da revista Anos 90. E-Mail: <alekerber@yahoo.com.br>.

${ }^{2}$ PRATS, Llorenç. Antropologia del patrimonio. Barcelona: Ariel, 2004.
} 
fato do tango passar a ser aceito e, até mesmo, valorizado por elites e segmentos médios argentinos, circulando entre vários grupos sociais e apresentando-se como possível síntese identitária nacional.

Nesse contexto, surgiram os primeiros artistas que se tornaram ídolos nacionais, tendo suas músicas difundidas nas várias regiões da Argentina, especialmente através dos novos meios de comunicação, que se massificavam nessa época: o rádio, o cinema e a indústria fonográfica. Carlos Gardel foi o mais importante desses artistas, foi o cantor popular de maior sucesso da Argentina nessa época, além de se manter até os dias atuais como figura representativa da identidade nacional argentina. Além disso, seu sucesso não se restringiu apenas às fronteiras argentinas, mas teve, também, um grande sucesso internacional, construindo um imaginário internacional acerca desse país.

Gardel teve sua consagração já em 1917, com a interpretação da canção "Mi noche triste", tango de Samuel Castriota e Pascual Contursi, canção considerada como um marco de uma nova fase na história do tango, a do "tango canción". Em toda sua carreira, gravou 930 canções e atuou em diversos filmes ${ }^{3}$.

Peluso e Visconti ${ }^{4}$, em seu livro sobre a repercussão do cantor na imprensa mundial, indicam, esta associação com a identidade nacional. Por exemplo, o "Anuario Teatral Argentino" de 1924 anunciava: "Es el dúo de cantos nacionales más popular de la República Argentina. Ellos cultivan con fidelidad e inimitable gusto, todo el cancionero típico porteño y folklorista argentino".

O próprio Gardel apresentava-se como uma síntese identitária nacional, articulando em suas músicas, imagem e performance elementos portenhos, gaúchos $e$ imigrantes (ele mesmo era um imigrante) $)^{5}$. Ao analisar a formação étnica argentina $e$ suas consequências sobre o tango, Martinez, Etchegaray e Molinari ${ }^{6}$ identificam dois grandes processos de choque cultural. $\mathrm{O}$ primeiro, seria o transcorrido durante o período colonial no violento encontro entre os espanhóis e as populações nativas americanas. Essa violência, que se expressava de diversas formas - desde a imposição de formas de trabalho, passando por estupros até assassinatos -, esteve presente de

${ }^{3}$ Gardel atuou, em 1930, em dez curtas nos quais, em cada um, canta um número de seu repertório: "Añoranzas"; "Cancero"; "Enfundá la mandolina"; "Mano a mano"; "El carretero"; "Padrino pelado"; "Rosa de otoño"; "Tengo miedo"; "Viejo smoking"; "Yira, Yira". Também atuou em "Luces de Buenos Aires" (1931), dirigido por Adelqui Millar (Paramount). "Esperame" (1932), dirigido por Luis Gasnier (Paramount); "La casa es seria" (1932), dirigido por Jaquelux (Paramount); "Melodía de arrabal" (1933), dirigido por Luis Gasnier (Paramount); "Cuesta Abajo" (1934), direção de Luis Gasnier (Paramount); "El tango en Broadway" (1934), dirigido por Luis Gasnier (Paramount); "The big broadcast of 1935" (1935), dirigido por Norman Taurog e Theodore Reed (Paramount). "En día que me quieras" (1935), dirigido por John Reinhardt (Paramount); "Tango Bar" (1935), dirigido por John Reinhardt (Paramount).

${ }^{4}$ ANUÁRIO Teatral Argentino, 1924, Apud PELUSO, Hamlet \& VISCONTI, Eduardo. Carlos Gardel y la prensa mundial. Buenos Aires: Corrigidor, 1998, p. 39.

${ }^{5}$ KERBER, Alessander. "A legitimação da identidade através da alteridade: a portuguesa Carmen Miranda como representante do Brasil nos Estados Unidos e o francês Carlos Gardel como representante da Argentina na Europa". Nuevo Mundo - Mundos Nuevos, Paris, CNRS/EHESS, vol. 10, 2010, p. 01-16. KERBER, Alessander. "Etnia, região e nação na Argentina do Entre-Guerras: um estudo das músicas e imagem de Carlos Gardel". Dialogos, Maringá, UEM, vol. 14, p. 579-603, 2010.

${ }^{6}$ MARTÍNEZ, Roberto Luis; ETCHEGARAY, Natalio; MOLINARI, Alejandro. De Garay a Gardel: la sociedad, el hombre común y el tango. (1580-1917). Buenos Aires: Biblioteca Nacional, 1998, p. 150. 
forma marcante quando da formação e emergência da cidade de Buenos Aires, já no século XVI, como ponto privilegiado de comércio que fazia escoar imensas riquezas em prata de Potosi para a Europa. Tais autores assinalam que, desde o início, Buenos Aires teve formação mestiça e a própria mestiçagem foi a responsável pela criação do gaucho, que, posteriormente, a partir do livro "Martin Fierro", tornou-se símbolo nacional argentino. O segundo grande choque ocorreu durante o intenso processo de imigração europeia entre o final do século XIX e início do XX.

Esse grande processo imigratório gerava um problema em relação à integração dessas populações. Conforme Prieto ${ }^{7}$, na época da Primeira Guerra, os nacionalistas argentinos já haviam encontrado no homem gaucho um símbolo que representava a herança cultural da nação sob a "ameaça" da imigração. Archetti ${ }^{8}$ afirma que, nesse contexto, o discurso nacionalista reviveu os temas "bárbaros" que tinham sido condenados a desaparecer por meio da imigração, da hibridação e da modernização. Essa reinvenção da tradição se tornou possível por causa do lugar privilegiado que a literatura gauchesca ocupava no consumo literário popular urbano e rural desde os anos 1880. Assim, a história do gaucho que lutava contra a injustiça do Estado a fim de manter sua liberdade foi transformada em modelo para uma "literatura nacional". A imagem do gaucho foi um elemento fundamental na construção da identidade nacional argentina. O sucesso de Martin Fierro e do circo criollo, a partir do final do século XIX, são provas disso.

Gardel, em sua trajetória artística, utilizou-se da imagem do gaucho tanto em sua carreira na Argentina quanto no exterior. Também se utilizou da imagem sofisticada das elites portenhas, já que servia aos padrões estéticos de beleza dessas elites, além de ter, em sua imagem, o jeito sofisticado delas. Gardel assimilava elementos simbólicos associados aos segmentos populares e de elite, de Buenos Aires e do interior argentino. Dessa forma, apresentou (e tornou-se) versão possível sobre a identidade nacional da Argentina, tendo elementos simbólicos que lhes permitiam a aceitação das elites e de diversos segmentos populares.

É possível afirmar que o próprio Gardel tinha esse projeto de representar a Argentina. Isso se manifesta em sua obra, na escolha de seu repertório, na aceitação a convites para atuar em filmes. No filme "Rosas de Otoño", gravado por Gardel em 1930 e dirigido por Eduardo Morera, por exemplo, o cantor tem uma atitude que parece um "prestar contas" para seu público de sua atuação internacional. Ao ser cumprimentado e questionado como está, responde, olhando para a câmera, ou seja, para o público: "Como siempre Hermano: dispuesto a defender nuestra lengua, nuestros costumbres y nuestras canciones [...]". O indagador da pergunta enfatiza, ainda, que ele está fazendo o possível para que "nossas canções" sejam conhecidas no mundo inteiro.

${ }^{7}$ PRIETO, Adolfo. El Discurso Criollista en la Formación de la Argentina Moderna. Buenos Aires: Sudamericana. 1988.

8 ARCHETTI, Eduardo P. "O 'gaucho', o tango, primitivismo e poder na formação da identidade nacional argentina”. Mana, Rio de Janeiro, FAPESP/ Museu Nacional, vol. 9, n. 1, 2003, p. 09-29. 


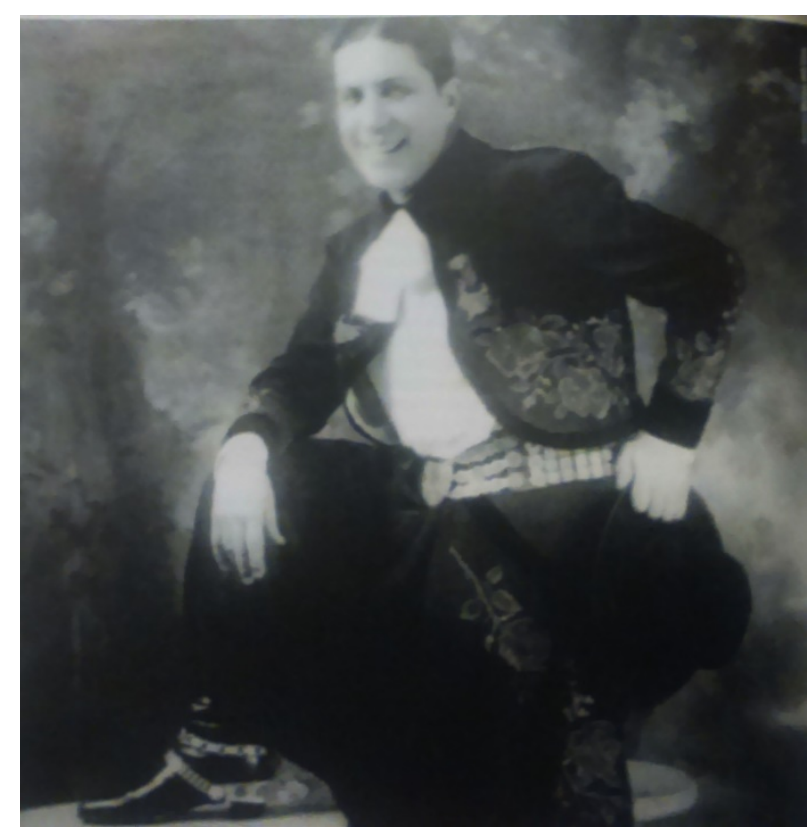

Fig. 1 - Foto de Gardel vestido de gaúcho, publicada no livro lançado na inauguração do Museo Casa Carlos Gardel ${ }^{9}$.

Essa atitude de Gardel nos indica que havia uma intencionalidade em mostrar-se para o público como representante nacional $e$, para tanto, misturou sua trajetória pessoal e musical. Quando perguntado sobre sua real nacionalidade por algum jornalista, Gardel respondia: "Mi patria es el tango', solía decir, o 'Soy ciudadano de la calle Corrientes" ${ }^{10}$. Evidentemente, era uma forma de burlar o imaginário social que o associava à Argentina enquanto que, na realidade, não havia nascido neste país.

Em diversas de suas canções, Gardel descreve o gaucho em seu espaço, na paisagem idealizada do campo que compõe o "mito fundador" da identidade nacional argentina. Existe uma composição nas roupas de Gardel que pode ser analisada em sua relação com as identidades regionais e nacional. Pode-se afirmar que, mesmo ele também apresentando uma certa diversidade em seu figurino, há duas imagens que se consagraram: a do gaúcho e a do homem sofisticado de Buenos Aires.

Por exemplo, no filme "El día que me quieras", de 1935, parece haver uma mescla, uma síntese dessas duas imagens. Gardel utiliza as vestimentas do gaúcho, mas há uma série de elementos que lembram o homem sofisticado de Buenos Aires. O chapéu usado por Gardel não é o tradicional, mas é o cosmopolitamente presente, nos anos 30, nas ruas de grandes cidades como Paris, Nova Iorque e... Buenos Aires. Também, percebe-se que o lenço amarrado no pescoço, peça típica da indumentária

\footnotetext{
9 MUSEOS de Buenos Aires - Dirección General. Para vos, morocho. Museo Casa Carlos Gardel. Buenos Aires: Gobierno de la Ciudad de Buenos Aires, 2003, p. 96.

${ }^{10}$ COLLIER, Simon. Carlos Gardel: su vida, su música, su época. Buenos Aires: Editorial Sudamericana, 1988, p. 91.
} 
do gaúcho, diferentemente dos outros dois gaúchos da imagem, está amarrado para o lado. Se não houvesse dois outros gaúchos com lenço no pescoço, quem visualizasse esta imagem provavelmente ficaria em dúvida se tratava-se de um lenço gaúcho ou de um cachecol, comumente usado por homens sofisticados de vários países de clima frio.

Para além de uma estética gaúcha, em algumas canções interpretadas por Gardel, há uma manifestação mais evidente de um nacionalismo argentino, como no caso da canção "Argentina", tango de Vicente Greco, gravado pelo cantor em 1924:

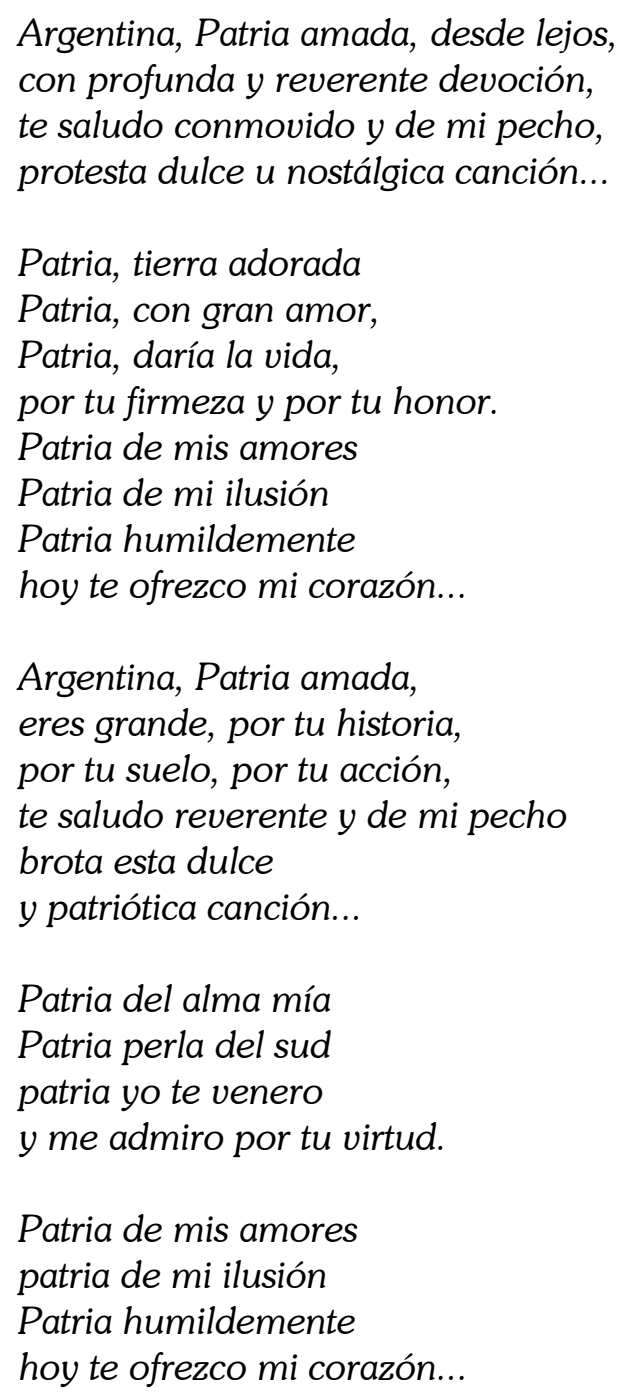

Perceba-se o ufanismo presente nesta música. A pátria Argentina é o ente para a qual Gardel oferece seu coração e sua vida. Outra canção, gravada por Gardel no ano seguinte de 1925, chamada "Salve, Patria", de Eugenio Cárdenas e Guillermo D. Barbieri: 
Salve patria de titanes, que se alzaron arrogantes, a los acordes vibrantes, del Himno de López y Planes. Quiero, Patria, en mis afanes de cantar tu bizarría, poner en mi alma bravía que las verdades no teme la bravura de tu Güemes y el verbo de Echeverria...

Patria, que en mayo, tu anhelo de libertad coronaste, y que tu enseña elevaste majestuosamente al cielo, quiero cantarle a tu suelo de onde el brazo proletario abre los surcos a diario con su pujante entereza como honrando la riqueza de tu suelo hospitalario.

En el sonoro cordaje de esta guitarra querida va un pedazo de mi vida como un lírico homenaje. Hoy te brindo mi lenguaje que en la estrofa se engalana, porque eres la soberana Patria, que su amor reparte y elevarte el estandarte de tu gloria americana.

Ainda, no ano de 1930, Gardel grava "Viva la patria", tango de Anselmo Aieta, letra de Francisco García Jiménez:

La niebla gris rasgó veloz, el vuelo de un adiós y fue el triunfal amanecer de la revolución y como ayer, el inmortal, mil ochocientos diez; salió a la calle el pueblo radiante de altivez. Ver un extraño el opresor cual de un siglo atrás, pero en el mismo el pabellón que quiso arrebatar, y al resguardar la libertad, del trágico malón la voz eterna y pura por las calles resonó:

Viva la patria y la gloria de ser libre. Viva la patria que quisieron mancillar. 
Orgulloso de ser argentino,

al trazar nuestros nuevos destinos, viva la patria, de rodillas en su altar.

Y la legión que construyó la nacionalidad, nos alentó, nos dirigió desde la eternidad, entrelazados vio avanzar la capital del sur, soldados y tribunos, linaje y multitud.

Amanecer primaveral de la revolución, de tu vergel, cada mujer fue una fragante flor y hasta tiño tu pabellón la sangre juvenil, haciendo más glorioso nuestro grito varonil.

Perceba-se que a exaltação da pátria se manifesta em todas estas músicas. Porém, nesta última, existe um conteúdo político mais explícito, no momento em que Gardel também exalta o "triunfal amanhecer da revolução" de 1810. Contudo, a data de gravação deste tango nos dá indícios para explicar esta forma de expressão. Trata-se de 1930, ano em que ocorreu o golpe que tirou do poder Yrigoyen. Neste sentido, Gardel parece expor, de forma mais clara, sua posição política do que nas canções anteriores, em que esta ficava ocultada apenas na exaltação da pátria como um todo. A exaltação de 1810 em 1930 parece estabelecer um continuum de glória entre estes dois momentos.

Nesse sentido, poder-se-ia afirmar que, Gardel construiu uma imagem misturando elementos de distintas identidades com o intuito de tornar-se representante da identitária nacional argentina. Gardel faz a síntese da antiga oposição entre a cidade de Buenos Aires, representada pela moda e os padrões europeus, e o campo, representado pelo gaúcho, a síntese entre a "civilização e a barbárie". A eficácia dessa representação nacional foi tanta que se manteve até a atualidade, mobilizando, por parte de muitos argentinos, homenagens, discursos de elogios inflamados, práticas de preservação de sua memória. Isso explica porque, desde os últimos anos do século $\mathrm{XX}$, quando as discussões sobre patrimônio imaterial iniciadas pela UNESCO passaram a circular entre os argentinos, houve um esforço para afirmar os diversos bens relacionados à memória de Gardel novamente como argentinos e portenhos.

\section{Gardel como Patrimônio Cultural na Argentina}

Os debates sobre patrimônio imaterial são recentes e distinguem-se da concepção de folclore, construída pelo Romantismo do século XIX. Apesar de poder se referir a bens culturais similares, como canções populares, a classificação deles como folclore ou como patrimônio imaterial implica em formas muito distintas de compreender esses bens. Ao abordar o folclore, autores como Canclini ${ }^{11}$ apontam críticas feitas a esse conceito na contemporaneidade, especialmente seus limites em termos de pensar a cultura como sendo estática. Em relação ao conceito de folclore também se

${ }^{11}$ CANCLINI, Nestor G. "O patrimônio cultural e a construção imaginária do nacional". Revista do Patrimônio Histórico e Artístico Nacional, n. 23, 1994, p. 95-115. 
desenvolvem críticas relacionadas à forma como ele foi constituído a partir de uma noção romântica de cultura associada à criação das identidades nacionais ${ }^{12}$.

Desde os últimos anos do século XX, a UNESCO passou a assumir a responsabilidade pela promoção do patrimônio cultural imaterial da humanidade $e$ iniciar, a seguir, o processo de inscrição desses bens. Artistas e intelectuais na Argentina e no Uruguai travaram uma disputa em termos de definir a qual destas duas nações pertencia o tango e Gardel. Numa tentativa de resolução do conflito, foi aprovado pela UNESCO, em 2009, o tango como patrimônio cultural imaterial da Argentina e do Uruguai. Perceba-se, nesse caso, a permanência de disputas nacionalistas iniciadas nos anos 1920 e 1930 acerca da "nacionalidade" do tango e do próprio Gardel tencionando esse processo de transformação desta arte em patrimônio imaterial.

Para o projeto que foi aprovado pela UNESCO em 2009, os governos de Argentina e Uruguai tiveram que se comprometer a realizar uma série de ações em ambos os lados do Rio da Prata para a preservação e promoção do tango como patrimônio imaterial da região platina, e não especificamente de uma nação. Contudo, percebe-se que essa disputa não se deu por encerrada após essa decisão da UNESCO. Por exemplo: entre as ações realizadas em ambos os lados do Prata para a promoção do tango como patrimônio imaterial superando as fronteiras nacionais estiveram a criação da "Biblioteca Nacional del Tango", em Montevidéu, e o apoio do governo argentino à "Academia Nacional del Tango", em Buenos Aires. Em relação a Gardel, os argentinos criaram o Museo Casa Carlos Gardel no local onde o artista residia no bairro do Abasto, em Buenos Aires. Os uruguaios criaram o Museu Carlos Gardel na cidade de Tacuarembó, cidade na qual o artista teria nascido ${ }^{13}$.

Há uma impressionante quantidade de biografias e outros livros publicados sobre Gardel e sua obra desde os anos 1920 até a atualidade, sendo a Argentina o país no qual há maior quantidade de publicações ${ }^{14}$. Uma das biografias mais recentes é a de

${ }^{12}$ Como as feitas por Anne-Marie Thiesse: THIESSE, Anne-Marie. "Ficções criadoras: as identidades nacionais". Anos 90, Porto Alegre, UFRGS, n. 15, 2001/2002.

${ }^{13}$ Há uma ampla bibliografia relacionada ao local de nascimento de Gardel. Essa bibliografia tem em comum a questão de Gardel ser um imigrante que chegou à Argentina na infância, acompanhado de sua mãe. A grande divergência refere-se ao lugar de onde ela teria vindo. Os uruguaios afirmam que ela veio de Tacuarembó, e o Museu Carlos Gardel criado nessa cidade tem a finalidade principal de comprovar isso, expondo diversas "provas" do nascimento do artista naquele local. Outra corrente, predominante entre argentinos e historiadores de outros países, como Simon Collier, afirma que Gardel nasceu na França. COLLIER, Carlos Gardel...

${ }^{14}$ BARCIA, José. Primer diccionario gardeliano. Buenos Aires: Corrigidor, 1991. BIANCO, Francisco. Recuerdos de Carlos Gardel. Buenos Aires: Buchier, s. d. CANTÓN, Darío. Gardel ¿a quién lê cantás? Buenos Aires: De La Flor, 1972. COUSELO, Jorge Miguel. Gardel, mito-realidad. Buenos Aires: A. Pena Lillo, 1964. DEFINO, Armando. Carlos Gardel: la verdad de una vida. Buenos Aires: Compañia General Fabril Editora, 1968. DELMAR, Alberto. Gardel, el encanto magnético: vida del cantor fascinente y retrato de una época. Buenos Aires: Vinciguerra, 1996. EICHELBAUM, Edmundo. Carlos Gardel. Buenos Aires: Javier Vergara, 1985. ESTEBAN, Juan Carlos. Carlos Gardel: encuadre histórico. Buenos Aires: Corregidor, 2003. FELDER, Elsa. Conociendo a Gardel. Buenos Aires: Imaginador, 1998. FERNÁNDEZ, Augusto. Carlos Gardel para todos. Buenos Aires: Porteñas, 1996. FERRER, Horacio. El tango: su historia y evolución. Buenos Aires: A. Peña Lillo Editor/ Ediciones Continente, 1999. GARCÍA JIMENEZ, Francisco. Carlos Gardel y su época. Buenos Aires: Corregidor, 1976. GRECO, Orlando Del. Carlos Gardel y los autores de sus canciones. Buenos Aires: Akian, 1990. GRÜNEWALD, José Lino. Carlos Gardel, lunfardo e tango. Rio de Janeiro: Nova Fronteira, 1994. 
Barsky e Barsky. Espantosamente, os autores criticam a falta de continuidade na produção de biografias de Gardel ${ }^{15}$. Isso pode parecer algo estranho, mas pode ser explicada pelo fato da grande presença de Gardel, nos dias atuais, no imaginário argentino, e a relação entre a identidade de Gardel e sua relação com as identidades portenhas ou argentinas estão entre os temas mais recorrentes nesses trabalhos.

A biografia escrita por Collier tem caráter ${ }^{16}$ mais acadêmico e é especificamente produzida por um historiador. A maior parte das biografias de Gardel, por outro lado, foram escritas por admiradores que as produziram de pontos de vista variados: jornalistas, músicos, literatos ou, mesmo, pessoas que se colocam sob o título muito geral de "escritores". Sem desqualificar todos estes trabalhos, os quais dão a sua contribuição produzindo olhares diferenciados sobre o objeto, temos que levar em conta que foram produzidos, em boa parte, sem preocupação acadêmica.

Outro elemento que denota a importância de Gardel para os argentinos está na criação de um centro de estudos especificamente relacionado a ele. O Centro de Estudos Gardelianos é definido como uma associação civil, sem fins lucrativos, inscrita na Inspección General de Justicia no dia 10 de dezembro de 2002. O Centro é composto por sujeitos de diversas formações acadêmicas que convergem em relação ao interesse em Gardel. Na página do Centro na internet está disponibilizada a organização administrativa do mesmo, sua composição, notícias, fotos $e$ artigos. Percebe-se que o Centro vincula-se a um grupo defensor da tese de que Gardel não é uruguaio. Há artigos sobre vários temas relacionados a Gardel, mas sobre o local de nascimento, apenas textos que afirmam que ele nasceu na França ou que ele não nasceu no Uruguai. Destaca-se o artigo "Invalidez de la documentación uruguaya de 1920", escrito por Juan Carlos Esteban, que explica justamente porque a documentação apresentada pelos uruguaios não confirma o nascimento de Gardel naquele país ${ }^{17}$.

No artigo "Carlos Gardel, el patrimonio que sonrie", Carozzi $1^{18}$, a partir de investigação etnológica que contava com observação das práticas realizadas em relação ao artista em lugares como seu túmulo, analisou a importância daquele artista para argentinos e, em especial, portenhos, naquele momento de comemoração dos 68 anos de seu falecimento. A autora afirma que Gardel goza de certa sacralidade, que na linguagem cotidiana "ser Gardel" significa ser excelente, que é um dos

HUET, Héctor Horacio. Carlos Gardel: el detalle que faltaba. Buenos Aires: Corregidor, 1995. LE PERA, José. Carlos Gardel: sus amigos, su última gira. Buenos Aires: Corrigidor, 1991. MACAGGI, José. L. Carlos Gardel: el resplendor y la sombra. Corregidor: Buenos Aires, 1987. MORENA, Miguel Angel. Historia artística de Carlos Gardel: estúdio cronológico. Buenos Aires. Buenos Aires: Corregidor, 1985. OREJA, Pablo Fermín. Carlos Gardel: un mito de los argentinos. Buenos Aires: Corregidor, 1999. ORGAMBIDE, Pedro. Un tango para Gardel. Buenos Aires: Sudamericana, 2003. PUNZI, Orlando M. La Argentina en la época de Gardel. Buenos Aires: Fundación Banco de la Província de Buenos Aires, 1986. VARELA, Sergio. Tangos que cantó Gardel. Buenos Aires: DISTAL, 1998.

15 BARSKY, Julian; BARSKY, Osvaldo. Gardel: la biografia. Buenos Aires: Aguilar, Altea, Aurus, Alfaguara, 2004, p. 19.

${ }^{16}$ COLLIER, Carlos Gardel...

17 ESTEBAN, Juan C. Invalidez de la documentación uruguaya de 1920. s.d. Disponível em: $<$ http://www.quienesgardel.com.ar/>. Acesso em: 14 jun. 2016.

18 CAROZZI, María J. "Carlos Gardel, el patrimônio que sonríe". Horizontes Antropológicos, Porto Alegre, PPGAS-UFRGS, ano 9, n. 19, 2003. 
defuntos mais famosos (e milagrosos) para os visitantes do cemitério da Chacarita, $e$ que o governo da cidade de Buenos Aires passou a promover o bairro do Abasto como o lugar onde viveu Gardel desde 1998, quando o tango passou a ser considerado patrimônio imaterial daquela cidade.

Ao explicar os motivos que levam a se mobilizar recursos para preservar e levar ao público o patrimônio, Lorenç Prats ${ }^{19}$ afirma justamente que isso se deve ao caráter simbólico do patrimônio e sua capacidade de representar simbolicamente uma identidade. Para o antropólogo, hoje em dia existe um consenso generalizado (ao menos nas ciências humanas) de que o patrimônio cultural é uma construção social, ou seja, que não existe naturalmente e não há critérios que sejam puramente objetivos em sua definição. Critérios apontados como pretensamente objetivos, como obsolescência, originalidade, antiguidade do bem, escassez, monumentalidade, entre outros, sempre estão articulados com outras questões subjetivas e com interesses dos grupos que se manifestam na defesa de que determinado bem deve ser valorizado como patrimônio.

As ações realizadas pelos argentinos para a promoção do tango e de Gardel como elementos identitários são anteriores às discussões sobre patrimônio imaterial e, podese afirmar que essas últimas, na Argentina, acabaram sendo uma continuidade das práticas de ativação patrimonial já realizadas anteriormente em relação ao tango e a Gardel. Desde 1977, os argentinos celebram o Dia Nacional do Tango, em 11 de dezembro, dia de nascimento de Carlos Gardel, e, em 1990, foi fundada a Academia Nacional Del Tango (pertence ao Ministério da Ciência e Tecnologia da Republica Argentina).

O Museo Casa Carlos Gardel, fundado em 04 de março de 2003, já se insere nesse contexto em que a noção de patrimônio imaterial é central. No mesmo ano da inauguração, o governo da cidade de Buenos Aires publicou um livro sobre esse museu $^{20}$, cujo prólogo é escrito pelo próprio chefe do governo da Cidade de Buenos Aires Aníbal Ibarra ${ }^{21}$. Interessante perceber que Ibarra é advogado e político, não um especialista em Gardel, nem em tango, mas se propõe a escrever sobrea importância de Gardel. Isso pode ser interpretado, talvez, como mais uma demonstração da própria importância de Gardel para Buenos Aires. O chefe de governo pode não ser especializado no tema, mas deve saber sobre os elementos da cultura importantes para a cidade.

A seguir, no mesmo livro, há uma nota preliminar, escrita por Jorge Telerman, o Secretário de Cultura da Cidade de Buenos Aires, um texto intitulado Un homenaje legítimo y necesario, escrito por Silvia Fajre, subsecretária do patrimônio cultural da cidade de Buenos Aires, um Prólogo del Editor, escrito por Mônica Guariglio, diretora geral de museus da cidade de Buenos Aires, e um texto intitulado La restauración del Museo Casa Carlos Gardel, escrito pelo arquiteto Martín Luis Italiano. Todos estes textos tem o mesmo objetivo: convencer o leitor de que a importância de Gardel para

\footnotetext{
${ }^{19}$ PRATS, Antropologia del patrimonio, p. 22.

${ }^{20}$ MUSEOS de Buenos Aires - Dirección General. Para vos, morocho. Museo Casa Carlos Gardel. Buenos Aires: Gobierno de la Ciudad de Buenos Aires, 2003.

${ }^{21}$ Candidato eleito em 2000 como chefe do governo da cidade pela Alianza para el Trabajo, la Justícia y la Educación, coalizão política que unia a União Cívica Radical e a Frente País Solidário.
} 
Buenos Aires é tanta que se faz necessário que o poder público realize investimentos como esses (do Museu e do livro) para a preservação e promoção da memória sobre esse artista.

A seguir, o livro traz uma sequência de artigos e imagens de Gardel. O primeiro artigo, escrito por Guadalupe Aballe, apresentada como docente, investigadora $e$ estudiosa da infância de Gardel, traz exatamente a versão sobre ele ter nascido na França (e não no Uruguai). Narra a autora:

El 11 e marzo de 1893 llega a Buenos Aires uma inmigrante francesa de 27 años llamada Berthe Gardés, com su pequeno hijo Charles, de 2 años y 3 meses de edad. Había dejado Toulouse, su Pueblo natal, movida por el afán de labrar um futuro mejor para ella y su hijo, lejos de los prejuicios que pesaban sobre su concición de madre soltera. ${ }^{22}$

É interessante perceber que os autores convidados para essa publicação são todos defensores dessa versão de um Gardel nascido na França. Contra essa versão se organizam autores uruguaios que defendem que Gardel nasceu em Taquarembó, no interior do Uruguai. As titulações acadêmicas e o poder simbólico desses intelectuais são utilizados para o convencimento dos leitores.

Para o caso uruguaio, um conjunto de autores publicou um livro em 2012 intitulado Gardel es uruguaio ${ }^{23}$. Essa publicação parece ser uma resposta à publicação de 2003 sobre o Museo Casa Carlos Gardel. Nela, todos os autores, de diferentes perspectivas e utilizando diversa documentação, afirmam a nacionalidade uruguaia de Gardel.

O site do Museo de Buenos Aires informa que "La casa que habitó Carlos Gardel junto a su madre fue recuperada por la Dirección General de Museos con la finalidad de convertirla en un espacio que rescata, conserva, exhibe y difunde el patrimonio cultural que representa la obra de Gardel" ${ }^{24}$. Nos objetivos da instituição, são informados que os mesmos relacionam-se à preservação e difusão do patrimônio, educação, fomento da arte, intercâmbio cultural $e$ teatro. Em relação à preservação $e$ difusão do patrimônio, afirma que o objetivo é:

Reunir una colección destacada de objetos diversos que pertenecieron a Carlos Gardel y a Berthe Gardès, que formaron parte de la casa de Jean Jaurès y que pueden contribuir a la reconstrucción histórica de la época y de las costumbres de vida del cantor y su madre. Organizar el material bibliográfico que se ocupa del tema de Carlos Gardel, del tango desde sus orígenes hasta el día de hoy, de la vida artística de Buenos Aires y del resto del país y el

\footnotetext{
${ }^{22}$ MUSEOS de Buenos Aires - Dirección General. Para vos..., p. 33.

${ }^{23}$ POSADA, Carlos (org.). Gardel es uruguayo. Montevideo: Ediciones de la Plaza, 2012.

24 MUSEO Casa Carlos Gardel. El Museo. s.d. Disponível em: < http://www.buenosaires.gob.ar/ museocasacarlosgardel/>. Acesso em: 14 jun. 2016.
} 
mundo en los tiempos del intérprete, para poder ponerla al servicio del lector nuevo como al investigador. Organizar una mediateca con las colecciones completas de la discografía de Garlos Gardel, en las diversas ediciones. Reunir los documentales que puedan haber tratado del tema de Carlos Gardel, de su época, de sus actuaciones, para sumarlo a la serie de producciones filmográficas. Disponer de todo el material existente en un registro que pueda ser consultado personalmente $y$ a través de internet. ${ }^{25}$

Ou seja, a instituição já se apresenta na perspectiva de promover a associação entre Gardel, Buenos Aires e Argentina.

O acervo do museu conta com discos e filmes de Gardel, objetos que pertenceram ao artista e uma biblioteca composta basicamente por obras sobre ele e sobre o tango na Argentina. Há uma exposição permanente em algumas das salas do museu. $\mathrm{Na}$ sala Hamlet Pelusso, estão expostos móveis, objetos e fotos associadas a momentos da vida de Gardel na Argentina. Na sala "Carlos Gardel suena en la radio", que era anteriormente o aposento no qual estava o escritório, se "intenta retratar la masividad de ese potente medio de comunicación y la penetración de la radiotelefonía en la cultura cotidiana en la ciudad. El tango mientras tanto cada día más popular se apropia de una gran porción de estas audiciones"

25 MUSEO Casa Carlos Gardel. Institucional. Objetivos. S.d. Disponível em: <http://www.buenosaires.gob.ar/museocasacarlosgarde>. Acesso em: 14 jun. 2016. 


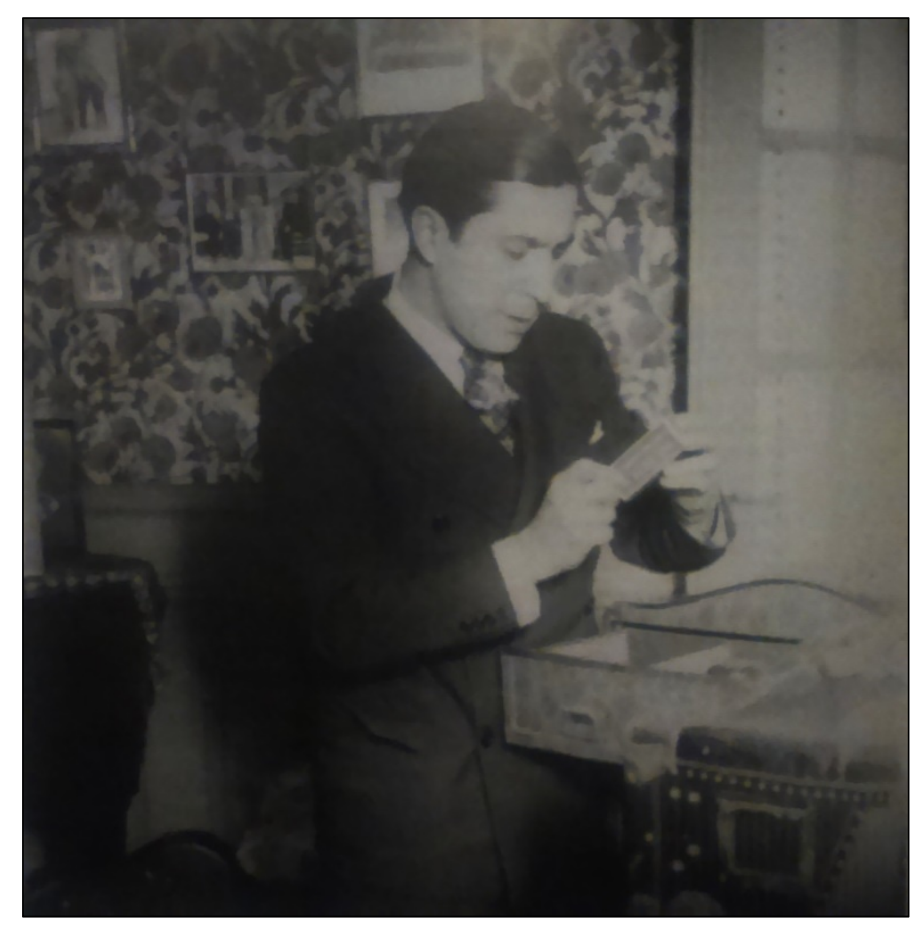

Fig. 2 - Gardel em sua casa. Foto publicada no livro lançado junto à inauguração do Museo Casa Carlos Gardel ${ }^{26}$.

O livro lançado sobre o Museo possui artigos de diversos autores que abordam diversas facetas de Gardel: o encontro de Gardel com o tango, os compositores das suas canções, seus filmes seu estilo, sua paixão pelo turfe, suas trajetórias em Paris e Nova Iorque, etc. De diversas formas, são estabelecidas relações de vínculo de Gardel com Buenos Aires ou como representante da Argentina no exterior. Alguns dos textos dedicam-se mais especificamente a isso. Em "Gardel Buenos Aires", de Eduardo Vázquez, é abordada justamente a identificação entre Gardel e os portenhos. Isso, segundo o autor, teria continuado a se desenvolver após seu falecimento: " $\mathrm{La}$ identificación del porteño con su figura se fue haciendo más abstracta com el paso del tiempo [...] Gardel fue para muchos el resumen de lo que generalmente se considera un porteño de ley a través del amor al barrio, a la madre, a la novia que todo lo perdona, a la creencia de que no hay país como el nuestro, etc." ${ }^{27}$

Percebe-se, nesse sentido, que as ações realizadas pelos argentinos, em especial pelo governo da cidade de Buenos Aires, denotam esse esforço em convencer sobre a identidade de Gardel ser argentina e portenha.

\section{Considerações Finais}

Ao viajar para a Argentina e para o Uruguai $e$ ao estabelecer contato com pesquisadores, admiradores e outros envolvidos nos debates sobre Gardel e o tango,

\footnotetext{
${ }^{26}$ MUSEOS de Buenos Aires - Dirección General. "Para vos, morocho...”. p. 114.

${ }^{27}$ MUSEOS de Buenos Aires - Dirección General. Para vos..., p. 141.
} 
recorrentemente sou indagado sobre minha "posição" em relação à nacionalidade do artista. Isso me parece ser indício de como esses temas são importantes para os nacionalismos argentino e uruguaio. A indagação sobre minha posição sobre onde nasceu Gardel parece soar como um: "De que lado você está?". Minha resposta, às vezes incompreendida ou vista como evasiva, é a de que não me posiciono sobre essa questão, de que não me interessa como tema de investigação qual foi o "verdadeiro" local de nascimento de Gardel. O que me interessa é investigar sobre como esse tema mobiliza argentinos e uruguaios, como o personagem Gardel e o tango são elementos importantes para a construção dessas duas identidades nacionais.

Em relação às práticas de ativação patrimonial realizadas na Argentina para a preservação de determinada memória sobre Gardel (e sobre o tango, sendo ambos indissociáveis) e sua promoção como patrimônio imaterial, concluo apontando para uma continuidade nas práticas realizadas pelos argentinos desde o tempo de vida do artista. As discussões sobre patrimônio imaterial, ao chegarem à Argentina entre o final do século XX e início do XXI serviram como mais um motivo para exaltar Gardel como representante da identidade nacional daquele país e para retomar as disputas com os uruguaios em relação à questão de sua nacionalidade.

\section{$\operatorname{soc}$}




\section{RESUMO}

No presente artigo, analiso as práticas de ativação patrimonial realizadas em Buenos Aires para promover Carlos Gardel como patrimônio imaterial dessa cidade e da nação argentina de 1998 até o final da primeira década do século XXI. Para tanto, utilizo, como fontes, a materialidade resultante dessas ações realizadas pelo governo municipal de Buenos Aires: a legislação estabelecida, as intervenções estabelecidas no bairro do Abasto - especialmente a criação do Museo Casa Carlos Gardel - e as publicações produzidas no intuito de afirmar Gardel como portenho e argentino. Em pesquisa realizada anteriormente, havia demonstrado como Gardel construiu uma versão sobre a identidade nacional argentina em suas músicas, imagem e performances, como o próprio artista frequentemente se apresentou como representante dessa nação e como essa versão teve sucesso entre os seus públicos argentinos (constituindo motivo de disputa com os uruguaios) no período entre 1916 e 1935. No presente artigo, abordando um contexto histórico muito distinto, demonstro como as discussões recentes acerca do patrimônio imaterial trouxeram novamente à tona um nacionalismo argentino verificável nas ações realizadas de promover Gardel como patrimônio argentino e portenho.

Palavras Chave: Patrimônio Imaterial; Carlos Gardel; Identidade Nacional Argentina; Buenos Aires.

Artigo recebido em 15 jun. 2016.

Aprovado em 22 ago. 2016.
ABSTRACT
In this article, I analyze the heritage activation practices conducted in Buenos Aires to promote Carlos Gardel as intangible heritage of that city and the Argentine nation from 1998 until the end of the first decade of this century. Therefore, I use as sources, the resulting materiality of these actions taken by the city government of Buenos Aires: the established legislation, interventions established in the district of Abasto especially the creation of the Museo Casa Carlos Gardel - and publications produced in order to affirm Gardel as porteño and argentine. In previously conducted research had shown as Gardel built a version of the Argentine national identity in their music, image and performance, as the artist himself often presented as representative of this nation and how this version had success among its Argentine public (constituting reason dispute with the Uruguayans) in the period between 1916 and 1935. In this article, addressing a very different historical context, demonstrate how the recent discussions about the intangible heritage brought to light again a verifiable Argentine nationalism in the actions taken to promote Gardel as Argentina and Buenos Aires heritage.

Keywords: Intangible Heritage; Carlos Gardel; Argentine National Identity; Buenos Aires. 